\title{
Both environmental tobacco smoke and personal smoking is related to asthma and wheeze in teenagers
}

\author{
Linnéa Hedman ${ }^{1,2}$ Anders Bjerg, ${ }^{1}$ Sigrid Sundberg, ${ }^{1}$ Bertil Forsberg, ${ }^{1,2}$ \\ Eva Rönmark ${ }^{1,2}$
}

- An additional table is published online only. To view this file, please visit the journal online (http://thorax.bmj.com).

${ }^{1}$ The OLIN-studies, Sunderby Central Hospital of Norrbotten, Luleå, Sweden

${ }^{2}$ Department of Public Health and Clinical Medicine,

Occupational and Environmental Medicine, Umeå University, Umeå, Sweden

\section{Correspondence to} Linnéa Hedman, The OLIN Study Group, Sunderby Central Hospital of Norrbotten, Robertsviksgatan 9, S-971 89 Luleå, Sweden; linnea.hedman@nll.se

Received 27 May 2010 Accepted 9 September 2010 Published Online First

3 November 2010

\section{ABST}

Background Environmental tobacco smoke (ETS) has been reported as a significant risk factor for childhood asthma. Among adults, personal smoking is a major cause of respiratory symptoms and diseases. The effects of these exposures on the prevalence of asthma and wheeze among teenagers are less well known. Objective The aim was to study the independent and combined effects of ETS and personal smoking on the prevalence of asthma and wheeze in teenagers.

Methods A longitudinal study of asthma and allergic diseases in schoolchildren has been in progress in Northern Sweden since 1996. All children aged 7-8 years in three municipalities were invited and 3430 (97\%) participants have been followed by annual questionnaires. At the age $16-17$ years, $82 \%$ of the initial participants took part in the 2005 survey.

Results Prevalence of physician-diagnosed asthma, ever wheeze and current wheeze was significantly higher among those exposed to maternal ETS and among daily smokers. In multivariate analyses, maternal ETS was a significant risk factor for physician-diagnosed asthma and ever wheeze (OR 1.3-1.5) and personal daily smoking for current wheeze (OR 2.0). ORs for asthma and ever wheeze were highest among daily smokers who were also exposed to maternal ETS with ORs of 1.7 and 2.5, respectively. A significant dose-response association between number of cigarettes/day and the prevalence of wheeze was also found.

Conclusions Both ETS and personal smoking were significantly related to asthma and wheeze in teenagers. Maternal ETS exposure was associated with lifetime symptoms, but daily smoking among the teenagers was more strongly related to current symptoms.

\section{INTRODUCTION}

Exposure to environmental tobacco smoke (ETS) in early life, especially that from the mother, and maternal smoking during pregnancy are known risk factors for respiratory symptoms and asthma among children. ${ }^{1-4}$ However, less is known of the association between ETS and respiratory symptoms and asthma in teenagers. Some studies found an increased risk for asthma and respiratory symptoms among young adults exposed to ETS in childhood $^{5}{ }^{6}$ or in utero ${ }^{7}$ while others have not found such associations. ${ }^{8}$

Smoking is a major cause of respiratory symptoms, chronic bronchitis and chronic obstructive pulmonary disease (COPD) among adults. ${ }^{9} 10$ The association between smoking and asthma among adults is not as strong or consistent. ${ }^{11}$ While crosssectional studies have primarily found relationships between asthma and ex-smoking or ever smoking, ${ }^{12}$ several longitudinal studies have found significant associations between current smoking and the onset of asthma. ${ }^{11314}$ Among teenagers, smoking is reported to be a risk factor for asthma and wheeze in both cross-sectional $^{15}$ and longitudinal studies. ${ }^{1} 78$ 16-19 Few studies have reported on the independent and combined effects of ETS and personal smoking on respiratory health among teenagers. In a French cross-sectional study, a higher risk of wheeze and asthma was found among smokers exposed to ETS compared to the non-exposed. ${ }^{15}$ Furthermore, in utero ETS exposure increases the risk of incident asthma among smoking teenagers. ${ }^{7}$

Within the Obstructive Lung Disease in Northern Sweden (OLIN) studies, a prospective cohort study about asthma and allergies among school children has been in progress since 1996. This study previously demonstrated associations between maternal smoking and prevalence of asthma at age $7-8$ years ${ }^{4}$ and increased incidence of asthma during the following 2 years. ${ }^{20}$ Parental smoking also increased the risk of smoking initiation during adolescence. ${ }^{21}$ The present study aimed to explore the independent and combined effects of ETS and personal smoking on the prevalence of asthma and wheeze among teenagers.

\section{MATERIAL AND METHODS Study population}

The OLIN paediatric study I is a longitudinal study about asthma, rhinitis, eczema and allergic sensitisation among school children in Northern Sweden that started in 1996. Its aims and methods have been described previously. ${ }^{4}$ The parents of all 3525 children aged 7 and 8 years who enrolled in the first and second grades in three municipalities in Northern Sweden were invited to complete a questionnaire. Ninety-seven per cent $(n=3430)$ participated, thus forming a cohort that has been followed by annual questionnaires. The study population in this paper consisted of 2805 children (50.5\% boys) who participated in 1996 and again in 2005 at the age of $16-17$ years (82\% of the original 1996 participants). The study was approved by the Ethics Committee at Umeå University, Sweden.

\section{Questionnaire}

The questionnaire included the International Study of Asthma and Allergies in Childhood (ISAAC) core 
questionnaire $^{22}$ with additional questions about symptoms, physician diagnosis of asthma and allergic diseases, parental smoking habits and other possible risk factors. ${ }^{23}$ Between ages 7-8 and 11-12 years, the questionnaire was completed by the parents. From 12 to 13 years of age and onwards, the teenagers completed the questionnaire at school and questions regarding personal tobacco use were added. ${ }^{21} 24$

\section{Definitions}

Definitions that were based on the 2005 questionnaire:

Ever wheeze: 'Have You ever had wheezing or whistling in the chest at any time in the past?'

Current wheeze: 'Yes' to any of the following: 'Have You had wheezing or whistling in the chest in the last 12 months?', 'In the last 12 months, has Your chest sounded wheezy during or after exercise?', 'In the last 12 months, have You had wheezing or whistling in the chest without having a cold?' or those reporting more than one attack in the question 'How many attacks of wheezing have You had in the last 12 months?'

Physician-diagnosed asthma: 'Have You been diagnosed by a physician as having asthma?'

Current asthma: Physician-diagnosed asthma, and either wheeze or use of asthma medication during the last 12 months.

Personal smoking habits were assessed by one question that was completed by all participants: 'Do you smoke?', and two follow-up questions directed to smokers: 'How often do you smoke?' and 'How much do you smoke?'

1. Occasional smokers: Smoking on weekends or at parties.

2. Daily smokers: Smoking 'Daily' or 'Almost daily'.

Definitions that were based on data from 1996 to 2005:

In utero exposure: Mother smoked during pregnancy

ETS at age 7-8 (16-17) years: Mother (father) smoked in 1996 (2005).

Continuous ETS: Mother (father) smoked at all surveys from 1996 to 2005.

Family history of asthma: Mother, father or sibling had asthma as reported in 1996.

Current place of residence: Living in a house, an apartment or both, as reported in 2004.

House dampness: A report of past or present dampness at home in any of the questionnaires from 1996 to 2005.

\section{Data management and statistical analysis}

For the lifetime outcomes (ever wheeze and physician-diagnosed asthma) and the current status (current wheeze and current asthma at $16-17$ years) missing answers to individual questions $(<1 \%)$ were coded as negative responses. Missing answers to questions about ETS exposure (4-7\%) and personal smoking $(<1 \%)$ were assigned the response given in the previous questionnaire.

Analyses were made using the computer software programme Statistical Package for Social Sciences (SPSS Version 16.0; SPSS Inc, Chicago, Illinois, USA). For assessment of differences in prevalence, $\chi^{2}$-tests were used and a $p$ value $<0.05$ was considered statistically significant. The effect of ETS and smoking on asthma and wheeze was analysed by multiple logistic regression analyses and expressed as ORs with 95\% CIs. All multivariate analyses included the covariates sex, family history of asthma, current place of residence, house dampness and low birth weight $(<2500 \mathrm{~g})$ because each is a known risk factor for asthma or related to personal smoking in this cohort. ${ }^{4} 2021$

Because maternal ETS and personal smoking are correlated, ${ }^{21}$ their effect was analysed in different multivariate models. In all models, the ETS variables were tested one at a time in separate analyses. Model A included maternal ETS and personal daily smoking, while Model B included maternal ETS and number of cigarettes smoked per day among the teenagers. Models $\mathrm{C}$ and $\mathrm{D}$ are presented in table S1 in the online supplement. In model C, only ETS variables were included and tested one at a time in separate analyses. Model D included four mutually exclusive exposure categories based on maternal ETS exposure and personal daily smoking. In a fifth model, the effect of maternal ETS exposure on asthma and wheeze was analysed among the non-smokers.

\section{RESULTS}

At age 7-8 years, the study population and those lost to followup reported almost identical prevalence of asthma and wheeze. However, the prevalence of ETS exposure at age 7-8 years was higher among those lost to follow-up compared to the study population; $40.0 \%$ vs $28.9 \%(p<0.001)$ were exposed from their mothers and $27.2 \%$ vs $21.4 \%(p<0.01)$ from their fathers.

\section{Prevalence of asthma and wheeze}

Among the 7-8-year olds, all asthma and wheeze variables were significantly more common among boys. At 16-17 years of age, both ever wheeze and current wheeze were more common among girls, while physician-diagnosed asthma and current asthma did not differ significantly by sex. The prevalence of all asthma and wheeze variables increased significantly by age (table 1 ). Among those with current wheeze at age 16-17 years, 41\% reported physician-diagnosed asthma. Of those with physician-diagnosed asthma and current asthma at age 16-17 years, 39\% and 38\%, respectively, reported physician-diagnosed asthma also in the 1996 survey at age 7-8 years.

\section{Prevalence of ETS exposure and smoking}

The prevalence of current maternal and paternal ETS exposure decreased significantly during the study period (table 1). Of the mothers who were current smokers in 2005, 60\% smoked during pregnancy and continuously during the study period. The prevalence of continuous ETS exposure was 14\% for maternal, $7 \%$ for paternal and 3\% were continuously exposed by both parents. Significantly more girls than boys had continuous exposure and current exposure to maternal ETS at age 16-17 years.

Daily smoking was significantly more common among girls, while occasional smoking was equally common among girls and boys (table 1 ). Of the daily smokers, $75 \%$ smoked $1-10$ cigarettes per day, and $55 \%$ of them currently had ETS exposure from at least one parent. Among the occasional smokers, 42\% reported current ETS exposure from at least one parent. These results were similar in boys and girls. The prevalence of daily smoking was $31 \%$ among those continuously exposed to maternal ETS compared to $7 \%(p<0.001)$ among those not continuously exposed. Smoking habits were similar among those with and without a family history of asthma.

\section{Asthma and wheeze in relation to ETS}

Statistically significant associations were found between all maternal ETS variables and physician-diagnosed asthma, ever wheeze and current wheeze with one exception: in utero exposure was not related to ever wheeze. Paternal ETS was not related to asthma or wheeze among the teenagers, except for ETS exposure at age 7-8 years, which was significantly associated with current wheeze at age 16-17 years (table 2). 
Table 1 Prevalence (\%) of asthma, wheeze, environmental tobacco smoke (ETS) exposure at age 7-8 and 16-17 years, and personal smoking habits at age $16-17$ years

\begin{tabular}{|c|c|c|c|c|c|c|c|}
\hline & \multicolumn{3}{|c|}{ Age $7-8$ years } & \multicolumn{3}{|c|}{ Age $16-17$ years } & \multirow[b]{2}{*}{$\begin{array}{l}\text { Difference by } \\
\text { age p value }\end{array}$} \\
\hline & $\begin{array}{l}\text { Boys } \\
(n=1416)\end{array}$ & $\begin{array}{l}\text { Girls } \\
(n=1389)\end{array}$ & $\begin{array}{l}\text { Difference by } \\
\text { gender } \mathbf{p} \text { value }\end{array}$ & $\begin{array}{l}\text { Boys } \\
(n=1416)\end{array}$ & $\begin{array}{l}\text { Girls } \\
(n=1389)\end{array}$ & $\begin{array}{l}\text { Difference by } \\
\text { gender p value }\end{array}$ & \\
\hline \multicolumn{8}{|l|}{ Outcome variables } \\
\hline Physician-diagnosed asthma & 7.5 & 4.2 & 0.001 & 13.6 & 13.0 & 0.680 & $<0.001$ \\
\hline Current asthma & 6.9 & 4.0 & 0.001 & 8.9 & 10.9 & 0.080 & 0.012 \\
\hline Ever wheeze & 24.8 & 17.5 & 0.001 & 21.9 & 26.1 & 0.010 & $<0.001$ \\
\hline Current wheeze & 11.4 & 8.3 & 0.007 & 16.5 & 24.8 & 0.001 & $<0.001$ \\
\hline \multicolumn{8}{|l|}{ Exposure to tobacco smoke } \\
\hline In utero exposure & 23.1 & 24.3 & 0.439 & - & - & & \\
\hline Current maternal ETS & 27.5 & 30.2 & 0.264 & 21.6 & 25.4 & 0.018 & $<0.001$ \\
\hline Current paternal ETS & 20.1 & 22.7 & 0.110 & 18.4 & 19.1 & 0.619 & 0.016 \\
\hline Continuous ETS mother & - & - & & 12.8 & 15.6 & 0.031 & \\
\hline Continuous ETS father & - & - & & 6.4 & 7.0 & 0.505 & \\
\hline \multicolumn{8}{|l|}{ Smoking habits } \\
\hline Occasional smokers & - & - & & 8.8 & 9.6 & 0.493 & \\
\hline Daily smokers & - & - & & 5.7 & 11.4 & $<0.001$ & \\
\hline
\end{tabular}

\section{Asthma and wheeze in relation to smoking}

The prevalence of physician-diagnosed asthma, ever wheeze and current wheeze was significantly higher among daily smokers compared to non-smokers (table 2). The prevalence of current asthma was slightly higher among daily smokers compared to non-smokers and the association was of borderline significance. Further, a significant dose-response association was found between the number of cigarettes smoked per day and the prevalence of physician-diagnosed asthma, ever wheeze and current wheeze (figure 1). The combination of current maternal ETS exposure and daily smoking yielded the highest prevalence estimates of all the asthma and wheeze variables (figure 2 ). The prevalence of asthma and wheeze did not differ significantly between non-smokers and occasional smokers (data not shown).

\section{Multivariate relationships}

In multivariate analyses, the associations between the different ETS variables and physician-diagnosed asthma remained significant or borderline significant with ORs of 1.3-1.5 (table S1;
Model C). Corresponding analyses for ever wheeze and current wheeze showed similar results. After adjusting to personal daily smoking among the teenagers (table 3; Model A) similar ORs for the ETS variables were obtained, but some of the associations became borderline significant. Daily smoking was significantly associated with ever wheeze and current wheeze (OR 1.9-2.0). A dose-response association between number of cigarettes smoked per day and the risk for ever wheeze and current wheeze was found (table 3; Model B). The highest ORs were obtained for the combination of being a daily smoker and currently ETS exposed with ORs of 2.6 (95\% CI 1.7 to 3.9) for ever wheeze, 2.3 (95\% CI 1.5 to 3.6) for current wheeze, and 1.7 (95\% CI 1.0 to 2.9) for physician-diagnosed asthma (table S1; Model D). No interaction between maternal ETS and personal daily smoking was found.

The effect of ETS was analysed separately among the nonsmokers. The multivariate analyses were similar to those for the whole study population and showed a positive association between ETS and physician-diagnosed asthma and ever wheeze (table 4).

Table 2 Prevalence (\%) of asthma and wheeze at age 16-17 years in relation to environmental tobacco smoke (ETS) and personal daily smoking

\begin{tabular}{|c|c|c|c|c|c|c|c|}
\hline & & $\begin{array}{l}\text { Physician- } \\
\text { diagnosed } \\
\text { asthma }\end{array}$ & $\begin{array}{l}\text { Difference } \\
\text { p value }\end{array}$ & $\begin{array}{l}\text { Ever } \\
\text { wheeze }\end{array}$ & $\begin{array}{l}\text { Difference } \\
\text { p value }\end{array}$ & $\begin{array}{l}\text { Current } \\
\text { wheeze }\end{array}$ & $\begin{array}{l}\text { Difference } \\
\text { p value }\end{array}$ \\
\hline \multicolumn{8}{|l|}{ Exposure to tobacco smoke } \\
\hline \multirow[t]{2}{*}{ In utero exposure } & No & 12.5 & 0.041 & 23.3 & 0.199 & 19.7 & 0.032 \\
\hline & Yes & 15.6 & & 25.7 & & 23.6 & \\
\hline \multirow{2}{*}{$\begin{array}{l}\text { Maternal ETS at age } \\
7-8 \text { years }\end{array}$} & No & 12.0 & 0.008 & 22.0 & 0.002 & 19.2 & 0.005 \\
\hline & Yes & 15.8 & & 27.5 & & 24.0 & \\
\hline \multirow{2}{*}{$\begin{array}{l}\text { Maternal ETS at age } \\
16-17 \text { years }\end{array}$} & No & 12.4 & 0.023 & 22.6 & 0.005 & 19.5 & 0.009 \\
\hline & Yes & 16.0 & & 27.9 & & 24.2 & \\
\hline \multirow[t]{2}{*}{ Continuous maternal ETS } & No & 12.5 & 0.002 & 22.9 & 0.002 & 19.9 & 0.016 \\
\hline & Yes & 18.1 & & 30.2 & & 25.1 & \\
\hline \multirow[t]{2}{*}{ Paternal ETS at age $7-8$ years } & No & 12.4 & 0.352 & 22.9 & 0.398 & 19.3 & 0.018 \\
\hline & Yes & 13.9 & & 24.6 & & 23.9 & \\
\hline \multirow{2}{*}{$\begin{array}{l}\text { Paternal ETS at age } \\
16-17 \text { years }\end{array}$} & No & 12.9 & 0.636 & 23.3 & 0.293 & 19.9 & 0.150 \\
\hline & Yes & 13.7 & & 25.5 & & 22.8 & \\
\hline \multirow[t]{2}{*}{ Continuous paternal ETS } & No & 13.3 & 0.847 & 23.9 & 0.972 & 20.2 & 0.050 \\
\hline & Yes & 12.8 & & 24.1 & & 26.2 & \\
\hline \multicolumn{8}{|l|}{ Smoking habits } \\
\hline \multirow[t]{2}{*}{ Daily smoking } & No & 12.9 & 0.025 & 22.8 & $<0.001$ & 19.3 & $<0.001$ \\
\hline & Yes & 18.0 & & 36.8 & & 34.7 & \\
\hline
\end{tabular}




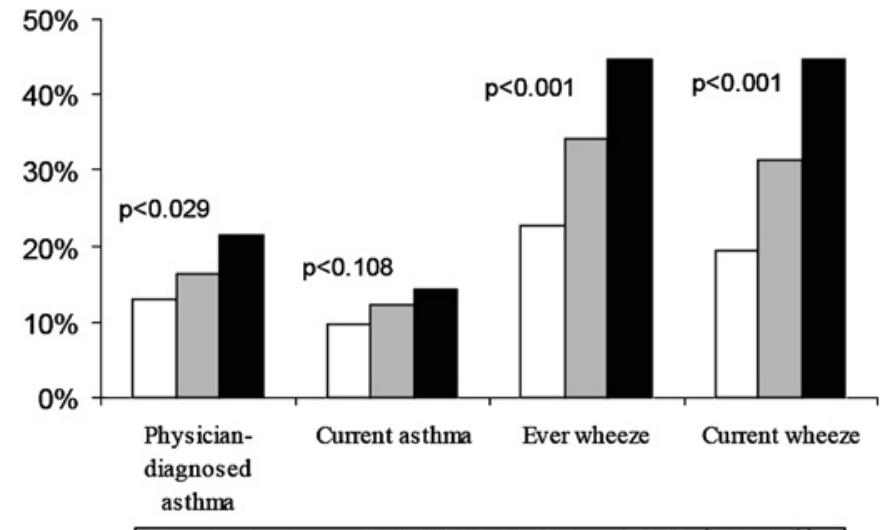

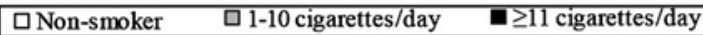

Figure 1 Prevalence (\%) of asthma and wheeze at age 16-17 years in relation to the number of cigarettes smoked per day by $\chi^{2}$-test for trend.

\section{DISCUSSION}

In this study, we found that both exposure to maternal ETS and personal smoking were independently related to asthma and wheeze among teenagers. Maternal ETS exposure was a significant risk factor for physician-diagnosed asthma, but the association between personal smoking and current wheeze was stronger. The prevalence of asthma and wheeze was highest among daily smokers who were exposed to maternal ETS.

The strong association between daily smoking and current respiratory symptoms is consistent with literature showing that smoking during adolescence is related to respiratory symptoms. ${ }^{1} 7815-19$ However, only few studies have reported on both the independent and the combined effects of ETS and personal smoking on respiratory health among teenagers. ${ }^{15} 19$ Both maternal ETS exposure and personal smoking were independently related to asthma and wheeze, and the combination of the two exposures yielded the highest risk of asthma and wheeze. Further, by age 16-17 years, we found a dose-response association with the highest prevalence of wheeze among those who smoked $\geq 11$ cigarettes per day. These results indicate that adverse effects of smoking occur within a few years of smoking initiation.

An important aspect to consider in studies of the effect of ETS exposure among teenagers is that the teenagers might be smokers. Teenagers with family members who smoke are at higher risk of being smokers themselves. ${ }^{21} 25$ Previous analyses of

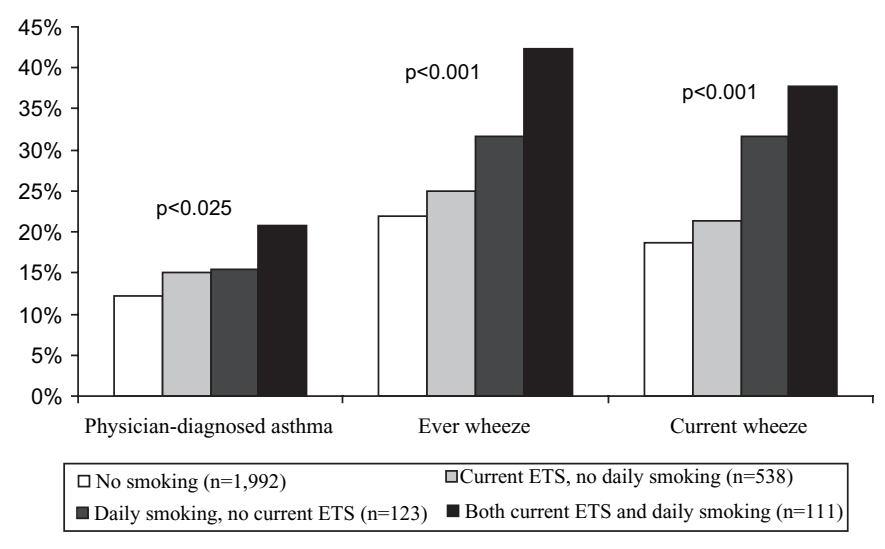

Figure 2 Prevalence (\%) of asthma and wheeze at age 16-17 years in relation to personal daily smoking and current maternal environmental tobacco smoke (ETS) exposure. the present cohort found a stepwise increase in prevalence of smokers with an increase in the number of smoking family members. ${ }^{21}$ In the present study, $55 \%$ of the daily smokers had a smoking parent, and thus it may be difficult to separate the effects of ETS and personal smoking. Although there were no statistically significant interactions, the ORs for both asthma and wheeze were highest among daily smokers exposed to ETS. This confirms the results from a limited number of previous studies that analysed the independent and combined effects of ETS exposure and personal smoking on asthma and wheeze. ${ }^{15} 19$ In contrast to a previous incidence study, ${ }^{8}$ we found independent effects of past and present ETS exposure on the prevalence of asthma also among non-smoking teenagers.

Our results support findings that maternal ETS exposure has a greater effect than paternal ETS exposure on the prevalence of asthma and wheeze. ${ }^{1} 19$ Previous studies of this cohort found that maternal smoking was associated with the prevalence of asthma at age $7-8$ years ${ }^{4}$ as well as incident asthma during subsequent years. ${ }^{20}$ In the present study, maternal ETS exposure remained a significant risk factor for the lifetime symptoms at 16-17 years, that is, physician-diagnosed asthma and ever wheeze, but not for current symptoms. One explanation for these results may be that the ETS exposure decreases as the children spend less time with their parents during adolescence compared to earlier. Another likely explanation may be that early ETS exposure is more important than late exposure and has an effect on respiratory health lasting into adolescence. Smoking during pregnancy is strongly related to fetal growth impairment, reduced lung function at birth and subsequent development of asthma. ${ }^{26} 27$ In line with our findings, Gilliland et al found in utero ETS exposure to be associated with physician-diagnosed asthma in childhood $^{3}$ and in adolescence, ${ }^{7}$ while postnatal ETS exposure was only associated with wheeze in childhood. ${ }^{3}$ However, in a British cohort study that followed participants from birth to age 33 years, the combination of ETS exposure in utero and at 16 years of age was associated with the development of asthma after 17 years of age. ${ }^{1}$ These inconsistencies may be explained by the use of different exposure and outcome time frames, or by the complex associations between pre- and postnatal ETS exposure and subsequent personal smoking.

At 7-8 years of age, ETS exposure was equally common among boys and girls. However, at age 16-17 years more girls were exposed to maternal ETS and more girls were daily smokers (table 1). Role modelling is important during adolescence. Having a smoking mother increases the risk of becoming a smoker. ${ }^{21}$ Thus, the explanation for the higher prevalence of maternal smoking among girls compared to boys might be that role modelling works in both directions-having a smoking daughter increase the likelihood that the mother continues to smoke.

Calculations of the incidence of asthma and wheeze in relation to tobacco smoke would have further strengthened our results. Despite that the annual incidence of asthma in teenagers is estimated at approximately $1 / 100$ per year, ${ }^{16}{ }^{17}$ the number of new cases with asthma and wheeze in our cohort was small, and further, the teenagers had smoked for a short period of time. Therefore, we were unable to study daily smoking as a risk factor for the incidence of asthma in this report. However, this will be an important issue in future follow-up studies of this population.

The strengths of this study include the longitudinal design, high participation rates and use of validated survey questions. The internationally used and validated ISAAC protocol was the source of questions about wheeze and asthma. The study design enabled reliable data of ETS exposure with less risk of recall bias. 
Table 3 Environmental tobacco smoke (ETS) exposure from the mother at different time points* and personal smoking as risk factors for asthma and wheeze at age $16-17$ years

\begin{tabular}{|c|c|c|c|c|c|c|c|}
\hline & & \multicolumn{2}{|c|}{ Physician-diagnosed asthma } & \multicolumn{2}{|c|}{ Ever wheeze } & \multicolumn{2}{|c|}{ Current wheeze } \\
\hline & & $\overline{\mathrm{OR}}$ & $95 \% \mathrm{Cl}$ & $\overline{\mathbf{O R}}$ & $95 \% \mathrm{Cl}$ & $\overline{O R}$ & $95 \% \mathrm{Cl}$ \\
\hline \multirow[t]{8}{*}{ Model A } & In utero exposure & 1.22 & 0.94 to 1.59 & 1.05 & 0.85 to 1.30 & 1.16 & 0.93 to 1.45 \\
\hline & Daily smoking & 1.33 & 0.91 to 1.94 & 1.87 & 1.39 to 2.52 & 1.97 & 1.46 to 2.67 \\
\hline & ETS at age $7-8$ years & 1.30 & 1.02 to 1.67 & 1.26 & 1.03 to 1.54 & 1.19 & 0.97 to 1.47 \\
\hline & Daily smoking & 1.32 & 0.90 to 1.93 & 1.88 & 1.40 to 2.53 & 1.96 & 1.45 to 2.66 \\
\hline & ETS at age $16-17$ years & 1.25 & 0.96 to 1.63 & 1.21 & 0.98 to 1.50 & 1.15 & 0.92 to 1.45 \\
\hline & Daily smoking & 1.36 & 0.93 to 1.98 & 1.89 & 1.41 to 2.55 & 1.99 & 1.47 to 2.70 \\
\hline & Continuous ETS & 1.47 & 1.09 to 1.99 & 1.34 & 1.04 to 1.71 & 1.18 & 0.91 to 1.54 \\
\hline & Daily smoking & 1.35 & 0.93 to 1.96 & 1.87 & 1.39 to 2.50 & 1.99 & 1.47 to 2.68 \\
\hline \multirow[t]{12}{*}{ Model B } & In utero exposure & 1.22 & 0.82 to 1.82 & 1.05 & 0.85 to 1.30 & 1.16 & 0.93 to 1.45 \\
\hline & $1-10$ cigarettes/day & 1.22 & 0.82 to 1.82 & 1.75 & 1.29 to 2.38 & 1.76 & 1.29 to 2.42 \\
\hline & $\geq 11$ cigarettes/day & 1.38 & 0.69 to 2.72 & 1.94 & 1.12 to 3.37 & 2.44 & 1.41 to 4.22 \\
\hline & ETS at age $7-8$ years & 1.31 & 1.02 to 1.68 & 1.26 & 1.03 to 1.54 & 1.19 & 0.97 to 1.47 \\
\hline & $1-10$ cigarettes/day & 1.18 & 0.78 to 1.77 & 1.68 & 1.23 to 2.29 & 1.74 & 1.26 to 2.39 \\
\hline & $\geq 11$ cigarettes/day & 1.32 & 0.67 to 2.62 & 1.98 & 1.15 to 3.41 & 2.34 & 1.35 to 4.05 \\
\hline & ETS at age $16-17$ years & 1.26 & 0.96 to 1.64 & 1.21 & 0.98 to 1.51 & 1.15 & 0.92 to 1.44 \\
\hline & $1-10$ cigarettes/day & 1.22 & 0.81 to 1.82 & 1.70 & 1.24 to 2.31 & 1.77 & 1.29 to 2.44 \\
\hline & $\geq 11$ cigarettes/day & 1.33 & 0.67 to 2.63 & 1.96 & 1.14 to 3.86 & 2.35 & 1.35 to 4.07 \\
\hline & Continuous ETS & 1.48 & 1.10 to 2.00 & 1.34 & 1.04 to 1.72 & 1.19 & 0.91 to 1.55 \\
\hline & $1-10$ cigarettes/day & 1.96 & 0.80 to 1.78 & 1.72 & 1.27 to 2.34 & 1.74 & 1.27 to 2.38 \\
\hline & $\geq 11$ cigarettes/day & 1.47 & 0.76 to 2.82 & 2.03 & 1.19 to 3.46 & 2.42 & 1.42 to 4.15 \\
\hline
\end{tabular}

ORs were calculated by multiple logistic regression analyses, adjusting for sex, family history of asthma, current place of residence, house dampness and birth weight $<2500 \mathrm{~g}$.

*The variables regarding ETS from the mother were included one at a time.

Limitations of the study are that we lack information about how much the mothers smoked during pregnancy and that detailed validation of the self-reported smoking habits has not been done. However, others have validated self-reported smoking by measuring cotinine levels and found good agreement. ${ }^{28}$ The reliability of the smoking reports in the present study is supported by the prevalence of smoking being similar to the Swedish average. ${ }^{24}$ Further, a comparative study between questionnaires completed by the parents and the teenagers in this cohort show very good agreement for the questions about parental smoking. ${ }^{29}$ In the present study, self-reported physi- cian-diagnosed asthma was not validated against objective methods. However, previous studies of the cohort have shown a very high specificity ${ }^{4}$ and a high agreement between parents and teenagers in the question about diagnosis of asthma. ${ }^{30}$

In conclusion, both ETS and personal smoking were significantly related to asthma and wheeze in teenagers. While exposure to maternal ETS was associated with lifetime symptoms, personal daily smoking was more strongly related to current symptoms. Effective smoking prevention programs among teenagers, particularly young women, are necessary to reduce the number of smokers and to improve public health.

Table 4 Environmental tobacco smoke (ETS) exposure from the mother as risk factor for asthma, ever wheeze and current wheeze in non-smokers at age $16-17$ years expressed as adjusted 0 Rs by multiple logistic regression analyses*

\begin{tabular}{|c|c|c|c|c|c|c|c|}
\hline \multirow[b]{3}{*}{ Independent variables } & \multirow[b]{3}{*}{ Categories } & \multicolumn{6}{|c|}{ Dependent variables } \\
\hline & & \multicolumn{2}{|c|}{ Physician-diagnosed asthma } & \multicolumn{2}{|c|}{ Ever wheeze } & \multicolumn{2}{|c|}{ Current wheeze } \\
\hline & & $\mathbf{O R}$ & $95 \% \mathrm{Cl}$ & $\overline{\mathbf{O R}}$ & $95 \% \mathrm{Cl}$ & $\overline{\mathbf{O R}}$ & $95 \% \mathrm{Cl}$ \\
\hline In utero exposure & Yes & 1.26 & 0.94 to 1.70 & 1.07 & 0.84 to 1.37 & 1.19 & 0.93 to 1.54 \\
\hline ETS at age $7 / 8$ & No & 1 & & 1 & & 1 & \\
\hline \multirow[t]{2}{*}{ ETS at age $16 / 17$} & No & 1 & & 1 & & 1 & \\
\hline & Yes & 1.40 & 1.04 to 1.88 & 1.26 & 0.98 to 1.61 & 1.20 & 0.92 to 1.56 \\
\hline \multirow[t]{2}{*}{ Continuous ETS exposure } & No & 1 & & 1 & & 1 & \\
\hline & Yes & 1.51 & 1.07 to 2.14 & 1.43 & 1.07 to 1.92 & 1.23 & 0.90 to 1.67 \\
\hline
\end{tabular}

*0ther variables included in the models were sex, family history of asthma, current place of residence, house dampness and birth weight $<2500 \mathrm{~g}$. The variables regarding ETS from the mothe were included one at a time. 
Acknowledgements Aina Jonsson, Kerstin Kemi Björnström and Lena Gustafsson are acknowledged for data collection.

Funding The Swedish Heart-Lung Foundation, The Swedish Foundation for Health Care Science and Allergy research (Vårdal), The Swedish Asthma-Allergy Foundation, the Swedish Research Council, the Norrbotten County Council and the JC Kempe Memorial Found for Scholarships are acknowledged for financial support. None of the funders had involvement in the study design, in the collection, analysis and interpretation of data, in the writing of the report, and in the decision to submit the paper for publication.

Competing interests None.

Ethics approval This study was conducted with the approval of the The Ethics Committee at Umeå University, Sweden.

Provenance and peer review Not commissioned; externally peer reviewed.

\section{REFERENCES}

1. Strachan DP, Butland BK, Anderson HR. Incidence and prognosis of asthma and wheezing illness from early childhood to age 33 in a national British cohort. BMJ 1996:312:1195-9.

2. Stein RT, Holberg CJ, Sherrill D, et al. Influence of parental smoking on respiratory symptoms during the first decade of life: the Tucson Children's Respiratory Study. Am J Epidemiol 1999;149:1030-7.

3. Gilliland FD, Li YF, Peters JM. Effects of maternal smoking during pregnancy and environmental tobacco smoke on asthma and wheezing in children. Am J Respir Crit Care Med 2001:163:429-36.

4. Rönmark E, Bjerg A, Hedman L, et al. The Obstructive Lung Disease in Northern Sweden (OLIN) longitudinal paediatric study I - the first 10 years. Clin Respir J 2008;2(Suppl 1):26-33

5. Svanes C, Omenaas E, Jarvis D, et al. Parental smoking in childhood and adult obstructive lung disease: results from the European Community Respiratory Health Survey. Thorax 2004;59:295-302.

6. Larsson ML, Frisk M, Hallström J, et al. Environmental tobacco smoke exposure during childhood is associated with increased prevalence of asthma in adults. Chest 2001:120:711-17

7. Gilliland FD, Islam T, Berhane $\mathrm{K}$, et al. Regular smoking and asthma incidence in adolescents. Am J Respir Crit Care Med 2006;174:1094-100.

8. Genuneit J, Weinmayr G, Radon K, et al. Smoking and the incidence of asthma during adolescence: results of a large cohort study in Germany. Thorax 2006; $61: 572-8$

9. Lundbäck B, Lindberg $A$, Lindström $M$, et al. Not 15 but $50 \%$ of smokers develop COPD? -report from the Obstructive Lung Disease in Northern Sweden studies. Respir Med 2003:97:115-22.

10. Mannino DM, Buist AS. Global burden of COPD: risk factors, prevalence, and future trends. Lancet 2007;370:765-73.

11. Sandström T, Lundbäck B. Tobacco smoke: old foe more important for asthma than commonly appreciated? Eur Respir J 2004:24:720-1.
12. Lötvall J, Ekerljung L, Rönmark EP, et al. West Sweden Asthma Study: prevalence trends over the last 18 years argues no recent increase in asthma. Respir Res 2009;10:94.

13. Rönmark E, Lundbäck B, Jönsson $E$, et al. Incidence of asthma in adults-report from the Obstructive Lung Disease in Northern Sweden Study. Allergy 1997:52:1071-8

14. Piipari R, Jaakkola JJ, Jaakkola N, et al. Smoking and asthma in adults. Eur Respir J 2004;24:734-9.

15. Annesi-Maesano I, Oryszczyn MP, Raherison C, et al. Increased prevalence of asthma and allied diseases among active adolescent tobacco smokers after controlling for passive smoking exposure. A cause for concern? Clin Exp Allergy 2004;34:1017-23.

16. Larsson L. Incidence of asthma in Swedish teenagers: relation to sex and smoking habits. Thorax 1995;50:260-4.

17. Norrman E, Nyström L, Jönsson E, et al. Prevalence and incidence of asthma and rhinoconjunctivitis in Swedish teenagers. Allergy 1998;53:28-35.

18. Withers NJ, Low L, Holgate ST, et al. The natural history of respiratory symptoms in a cohort of adolescents. Am J Respir Crit Care Med 1998;158:352-7.

19. Van de Ven MO, Engels RC, Kerstjens HA, et al. Bidirectionality in the relationship between asthma and smoking in adolescents: a population-based cohort study. J Adolesc Health 2007:41:444-54.

20. Rönmark E, Perzanowski M, Platts-Mills T, et al. Incidence rates and risk factors for asthma among school children: a 2-year follow-up report from the obstructive lung disease in Northern Sweden (OLIN) studies. Respir Med 2002:96:1006-13.

21. Hedman L, Bjerg A, Perzanowski M, et al. Factors related to tobacco use among teenagers. Respir Med 2007;101:496-502.

22. Asher MI, Keil U, Anderson HR, et al. International Study of Asthma and Allergies in Childhood (ISAAC): rationale and methods. Eur Respir J 1995;8:483-91.

23. Rönmark E, Bjerg A, Perzanowski $\mathrm{M}$, et al. Major increase in allergic sensitization in schoolchildren from 1996 to 2006 in northern Sweden. J Allergy Clin Immunol 2009;124:357-63.

24. The National institute of public health. Health behaviour in school-aged children in Sweden-A WHO collaborative study. Sweden: Folkhälsoinstitutet, 2003.

25. O'Callaghan FV, O'Callaghan M, Najman JM, et al. Prediction of adolescent smoking from family and social risk factors at 5 years, and maternal smoking in pregnancy and at 5 and 14 years. Addiction 2005;101:282-90.

26. Cook DG, Strachan DP. Health effects of passive smoking 10: Summary of effects of parental smoking on the respiratory health of children and implications for research. Thorax 1999;54:357-66

27. Leonardi-Bee J, Smyth A, Britton J, et al. Environmental tobacco smoke and feta health: systematic review and meta-analysis. Arch Dis Child Fetal Neonatal Ed 2008;93:F351-61.

28. Post A, Gilljam H, Rosendahl I, et al. Validity of self reports in a cohort of Swedish adolescent smokers and smokeless tobacco (snus) users. Tob Control 2005;14:114-17.

29. Hedman L, Bjerg A, Perzanowski M, et al. Good agreement between parental and self-completed questionnaires about allergic diseases and environmental factors in teenagers. J Clin Epidemiol 2010;63:783-9.

30. Hedman L, Lindgren B, Perzanowski M, et al. Agreement between parental and selfcompleted questionnaires about asthma in teenagers. Pediatr Allergy Immunol 2005;16:176-81 